\title{
Shaping ability of rotatory or reciprocating instruments in curved canals: a micro-computed tomographic study
}

\author{
Alexander Pompermayer JARDINE \\ Ricardo Abreu da ROSA \\ Manuela Favarin SANTINI \\ Ivana Maria ZACCARA \\ Marcus Vinicius Reis SÓ \\ Patrícia Maria Poli KOPPER
}

Universidade Federal do Rio Grande do Sul - UFRGS, Graduate Program in Dentistry, Department of Conservative Dentistry, Porto Alegre, RS, Brazil.

Declaration of Interests: The authors certify that they have no commercial or associative interest that represents a conflict of interest in connection with the manuscript.

\section{Corresponding Author:}

Patrícia Maria Poli Kopper

E-mail: patricia.kopper@ufrgs.br

DOI: 10.1590/1807-3107BOR-2016.vol30.0086

Submitted: Nov 06, 2015

Accepted for publication: Mar 06, 2016

Last revision: Apr 25, 2016
Abstract: This study aimed to compare apical transportation, centering ratio, and working time during root canal preparation with Wizard Navigator (WN), WaveOne (WO), or ProTaper Universal (PT) and to describe deformation and fracture of these instruments. Thirty-six mesiobuccal roots from maxillary molars were micro-computed tomography (micro-CT) scanned and then sorted into three groups ( $\mathrm{n}=12)$ : Wizard Navigator $(\mathrm{WN})$, WaveOne (WO), and ProTaper Universal (PT). The root canals were prepared using $\mathrm{WN}$, WO, or PT; the time of each canal preparation was timed; and the specimens were micro-CT re-scanned. The instruments were submitted to scanning electron microscopy (SEM) before and after their use. The data on canal transportation at 1, 2, 3, 4 and $5 \mathrm{~mm}$ and preparation time were analyzed by the Kruskal-Wallis test, followed by the Mann-Whitney U test. The centering ratio was analyzed by ANOVA, followed by Tukey's test. Both instrument deformation and fracture were described. Apical transportation was similar among groups at 1, 2, 3 and $4 \mathrm{~mm}$. The WO group showed higher canal transportation at $5 \mathrm{~mm}$ than the other groups $(p=0.03)$. There was no significant difference in centering ratio among the groups. Preparation time in the WO group was significantly lower than in the other groups $(p=0.004)$. Small differences were observed in the surface area of all instruments. The WN, WO, and PT groups had a similar centering ratio without procedural errors or significant structural changes. At $5 \mathrm{~mm}$ from the apex, the WO group showed the largest canal transportation toward the furcation and root canal preparation was faster than in the WN and PT groups.

Keywords: Reciprocating Instrument; Rotatory Instrument; Micro-CT; Root Canal Preparation.

\section{Introduction}

The success of endodontic treatment depends on several factors, ${ }^{1}$ including the preservation of the original root canal anatomy. ${ }^{1}$ Nickel-titanium (NiTi) instruments were designed to improve the ability to maintain the original shape of curved canals after their preparation. ${ }^{2,3}$ This can be attained thanks to their elastic behavior and elastic memory., ${ }^{4,5}$

Regardless of the advantages of rotary NiTi instruments, they appear to have a high risk of fracture. ${ }^{6}$ The variables that contribute to deformation and fracture of these instruments include root curvature radius, diameter and 
design of the instrument, cross-sectional area, torque and rotation speed, technique used, and expertise of the health professional. ${ }^{7,8,10}$ Surface treatments of metals and metallurgical characterization of NiTi alloys also influence the morphological changes and may decrease the rates of fracture. ${ }^{11,12}$

The Wizard Navigator (Medin, Nové Město na Moravě, Czech Republic) is a rotary system in which NiTi instruments have a triangular section and an inactive tip. This system provides constant taper throughout the sequence of instruments used, while the Protaper Universal System (Dentsply Maillefer, Ballaigues, Switzerland) shows a variable taper. The system consists of six instruments: W1 (10/.04), W2 (15/.05), W3 (20/.06), W4 (25/.06), W5 (30/.06), and WXN (25/.07).

The WaveOne (Dentsply Maillefer, Ballaigues, Switzerland) was introduced as a single-file technique, used in reciprocating motion and made of a special NiTi alloy (M-wire). According to the literature, its advantages include increased flexibility, improved resistance to cyclic fatigue, and minimal canal transportation. ${ }^{13,4,15}$

Knowledge about the shaping effects and about the changes in the NiTi instrument surface area is important for the selection of the appropriate instrument and technique. As the behavior of Wizard Navigator (WN) has been poorly described, the present study aimed to compare apical transportation and centering ratio after root canal preparation with $\mathrm{WN}$, WO, and PT instruments, using micro-computed tomography (micro-CT), to describe deformation and fracture of the tested instruments and to compare working time during root canal preparation.

\section{Methodology}

The present study was approved by the Research Ethics Committee of the Federal University of RioGrande doSul, Porto Alegre, Brazil (CAAE-08758212.1.0000.5347).

\section{Sample selection}

A total of 36 mesiobuccal roots from extracted human permanent first maxillary molars were selected. Root canals that did not allow the insertion of a $10 \mathrm{~K}$-file into the major foramen or the passive placement of a $15 \mathrm{~K}$-file at $1 \mathrm{~mm}$ before the apical foramen were replaced. The working length $(\mathrm{WL})$ was established at $1 \mathrm{~mm}$ short of the canal length by the visual method.
Then, the apical foramina were sealed with wax and each root was fixed to a custom-made jig.

All the specimens were initially scanned by micro-CT using Skyscan 1172 (SKYSCAN, Kontich, Belgium). Exposure parameters were set at $100 \mathrm{kV}$ and $100 \mu \mathrm{A}$, with a $26 \mu \mathrm{m}$ isotropic resolution. After scanning, root canal curvatures were determined mathematically by measuring the angle and radius according to Schneider's method ${ }^{16}$ The mean angle of curvature ranged from 20 to 30 degrees. An equal number of roots with similar degrees of curvature and radius were randomly distributed into three groups $(n=12)$ : Wizard Navigator $(\mathrm{WN})$, WaveOne (WO), and ProTaper Universal (PT).

\section{Root canal preparation and irrigation}

A single trained operator performed root canal instrumentation using the $X$-Smart Plus micro-motor (Dentsply Maillefer, Ballaigues, Switzerland). For each system, the motion and sequence of instruments followed the manufacturers' instructions, and WO primary instrument was selected for the WO group (Table 1). In the WN and PT groups, the canals were irrigated with $1 \mathrm{~mL}$ of $1 \%$ sodium hypochlorite after each instrument change. In the WO group, the

Table 1. Sequence of instruments used for preparation of the root canals in each group: Wizard Navigator (WN), WaveOne (WO), and ProTaper Universal (PT).

\begin{tabular}{|c|c|c|}
\hline WO & WN & PT \\
\hline \#15 K-file to the WL & \#15 K-file to the WL & \#15 K-file to the WL \\
\hline 25.08 to the $W L$ & 25.07 until resistance & S1 until resistance \\
\hline \#15 K-file to the WL & \#15 K-file to the WL & \#15 K-file to the WL \\
\hline- & 10.04 to the WL & S2 until resistance \\
\hline- & \#15 K-file to the WL & \#15 K-file to the WL \\
\hline- & 15.05 to the WL & S1 to the WL \\
\hline- & \#15 K-file to the WL & \#15 K-file to the WL \\
\hline- & 20.06 to the $W L$ & S2 to the WL \\
\hline- & \#15 K-file to the WL & \#15 K-file to the WL \\
\hline- & 25.06 to the WL & $\mathrm{Fl}$ to the $\mathrm{WL}$ \\
\hline- & \#15 K-file to the WL & \#15 K-file to the WL \\
\hline- & - & F2 to the WL \\
\hline- & - & \#15 K-file to the WL \\
\hline
\end{tabular}

WL: working lenght. 
instrument was removed and cleaned after three pecking motions and the canal was irrigated with the same solution. Each instrument was employed in four root canals.

\section{Apical transportation and canal centering ratio}

After instrumentation, all the root canals were micro-CT re-scanned using the same sets described in the first analysis. Cross-sectional micro-CT images at 1, 2,3, 4 and $5 \mathrm{~mm}$ from the apical foramen (pre- and post-instrumentation) were analyzed using the CT Analyzer software (SKYSCAN, Kontich, Belgium) to evaluate the effects of instrumentation on apical transportation and centering ratio. One calibrated evaluator measured all values (ICC $=0.94)$. Canal transportation and centering ratio values were determined by measuring the shortest distance from the edge of the canal to the periphery of the root (mesially and distally). Then, pre- and post-instrumentation values were compared across samples. ${ }^{17}$

The following formulas were used for calculating canal transportation and centering ratio: $\left.\mid\left(\mathrm{x}_{1}-\mathrm{x}_{2}\right)-\mathrm{y}_{1}-\mathrm{y}_{2}\right) \mid$ and $\left(\mathrm{x}_{1}-\mathrm{x}_{2}\right) /\left(\mathrm{y}_{1}-\mathrm{y}_{2}\right)$ or $\left(\mathrm{y}_{1}-\mathrm{y}_{2}\right) /\left(\mathrm{x}_{1}-\mathrm{x}_{2}\right)$, respectively. $\mathrm{x}_{1}$ and $\mathrm{x}_{2}$ are the shortest distance from the mesial edge of the root to the mesial edge of the pre- and post-instrumented canal, respectively; and $\mathrm{y}_{1}$ and $\mathrm{y}_{2}$ are the shortest distance from the distal edge of the root to the distal edge of the pre and post-instrumented canal, respectively. A result other than 1 indicates canal transportation and a result equal to 1 indicates perfect centering. ${ }^{17}$

\section{Deformation and fracture of the instruments}

The WN, WO, and PT instruments were unpacked, scrubbed, and sonic cleaned using Riozyme II enzymatic detergent (Rioquímica, São José do Rio Preto, Brazil). Then, the WO primary instrument, the $\mathrm{W} 4 \mathrm{WN}$, and the F2 PT instruments were submitted to scanning electron microscopy (SEM) using Philips XL 30 (Philips, Amsterdam, Netherlands). Two observers analyzed $180^{\circ}$ of the instrument circumference, investigating body deformations. Two images of each instrument at 100X magnification were recorded: one from the tip up to $2.5 \mathrm{~mm}$ and one between
$2.5 \mathrm{~mm}$ and $5 \mathrm{~mm}$. After these procedures, all the instruments were individually re-packaged and numbered from 1 to 3 .

After root canal preparation, each W4 (WN), WO primary instrument, and F2 (PT) instrument was re-analyzed by SEM, utilizing the same sets described in the first analysis. All the SEM images (pre- and post-instrumentation) were coded and stored digitally. Two blinded examiners classified the images according spiral distortion, surface wear, and fracture. ${ }^{18}$

\section{Working time}

The instrumentation time of each root canal was timed using a digital timer (SportLine, Elmsford, United States). The timer was started when the first $\mathrm{WN}, \mathrm{WO}$ or PT instrument was introduced into the canal and turned off when the last instrument of the sequence (or when the WO primary instrument) reached the WL.

\section{Statistical analysis}

Data analyses were performed using SPSS 17.0 (IBM, New York, United States). The Kruskal-Wallis test, followed by the Mann-Whitney U test, was used for comparison between groups regarding canal transportation at each millimeter assessed and instrumentation time. One-way analysis of variance, followed by Tukey's post-hoc test, was used for comparisons of the centering ratio data. The significance level was set at $5 \%$ for all statistical tests.

\section{Results}

At 1, 2, 3 and $4 \mathrm{~mm}$, there were no significant differences in canal transportation among the groups ( $p>0.05)$. At $5 \mathrm{~mm}$, the $\mathrm{WN}$ and PT groups promoted less canal transportation than the WO group $(p=0.03)$. There were no significant differences among the canal levels within the same group ( $p>0.05$ ) (Figure 1). It is important to point out that at a $5 \mathrm{~mm}$ section, most canals instrumented by WO (75\%) transported towards the furcation (distal canal wall) while most canals instrumented by PT (67\%) and WN (73\%) transported towards the mesial canal wall (Figure 2). At 3,4 and $5 \mathrm{~mm}$, a greater variation in centering ratio was observed in all groups. No significant differences were observed among the different levels considering the same group $(\mathrm{p}>0.05)$ (Figure 3$)$. 


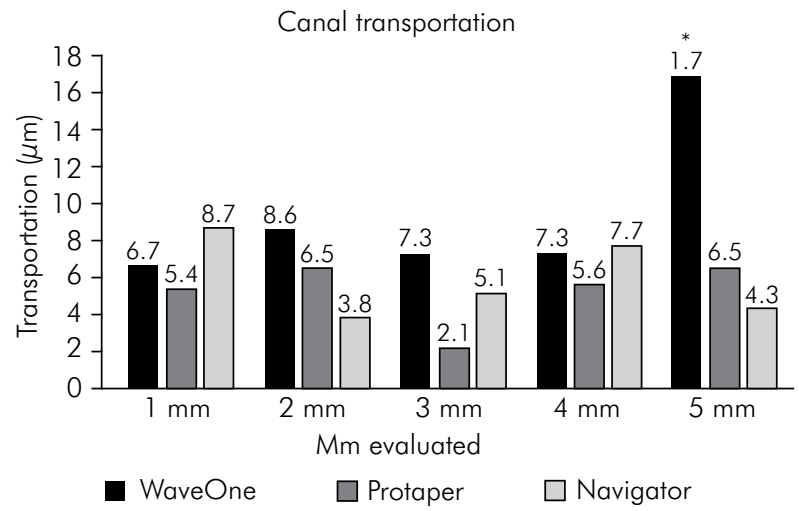

*represents significant difference between groups in the same-level section.

Figure 1. Median of canal transportation $(\mu \mathrm{m})$ in the WaveOne, ProTaper, and Wizard Navigator groups.
A

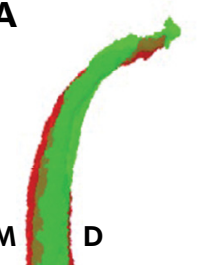

B

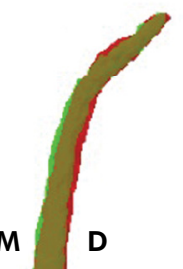

C

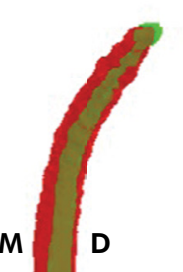

Figure 2. Mesiodistal view (" $M$ " mesial; " $D$ " distal) of three-dimensional reconstruction of the mesiobuccal root canals from mandibular first molars representative of the Wizard Navigator group (A), WaveOne group (B), and ProTaper group (C). Green indicates preoperative area; red indicates postoperative area. Major dentin wear towards the mesial canal wall in " $\mathrm{a}$ " (Wizard Navigator group) and in " $\mathrm{c}$ " (ProTaper group) and towards the furcal region in " $b$ " (WaveOne group).
Figure 4 illustrates theSEM findings. Before rootcanal instrumentation, all images of the tested instruments presented no unwinding, reverse winding, or shortening of spirals and no wear along the shaft examined. After instrumentation, thesameconditions were observed in WN instruments. In the WO and PT groups, all instruments presented one to three areas with defects along the examined shaft. Moreover, no fracture was detected.

Root canal instrumentation was significantly faster in the WO group than in the WN and PT groups $(p=0.004)($ Table 2$)$.

\section{Discussion}

Aiming to improve canal shaping, cutting efficiency, flexibility, and safety, new NiTi systems with different designs have been launched on the market. This ex vivo study compared an understudied rotatory system (Wizard Navigator) with two well-known systems (WaveOne and ProTaper Universal) using SEM and micro-CT.

This study evaluated a single-file technique with reciprocating motion and two different rotary systems using micro-CT and SEM. A number of methods have been used to compare canal shape before and after instrumentation, such as radiography and serial sectioning. ${ }^{15,19}$ However, micro-CT proves to be appropriate for the evaluation of changes in root canal shaping, resulting in high-resolution images and allowing accurate comparison of the same tooth pre- and post-instrumentation. ${ }^{20,21,22}$

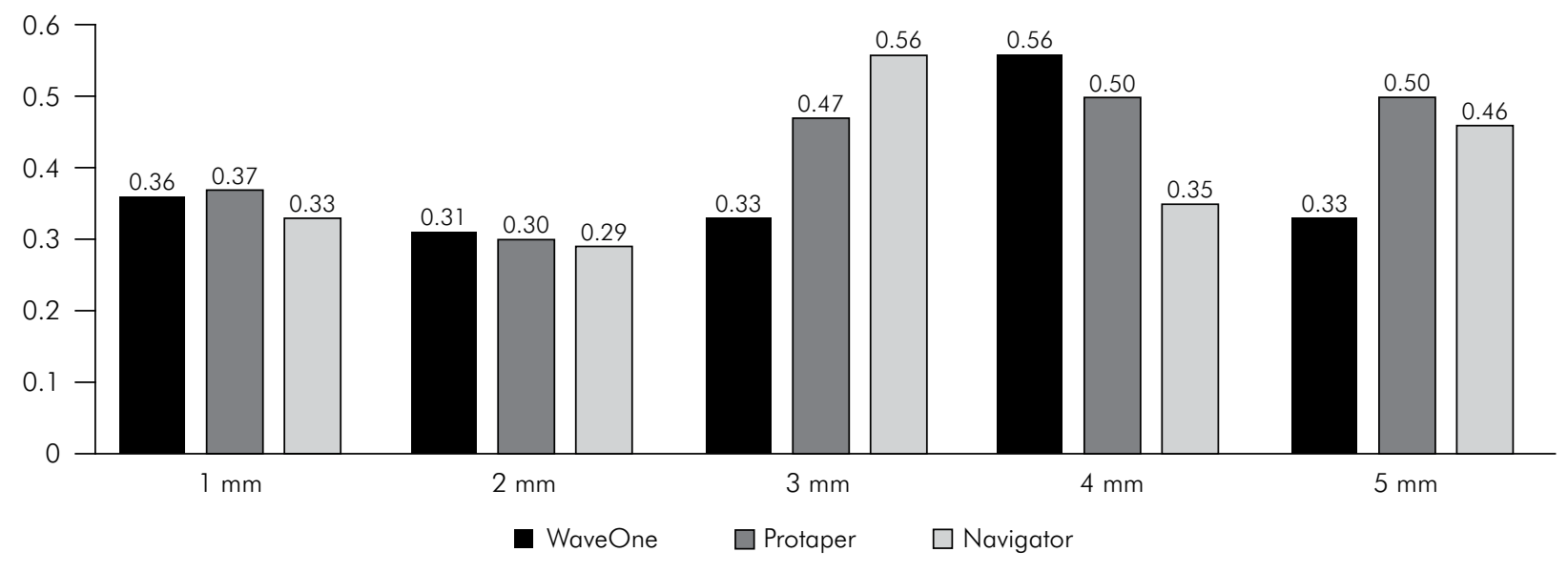

$*<0.05$

Figure 3. Centering ratio. A result of one indicates perfect centering ability; the closer the result is to zero, the worse the ability of the instrument to remain centered. 

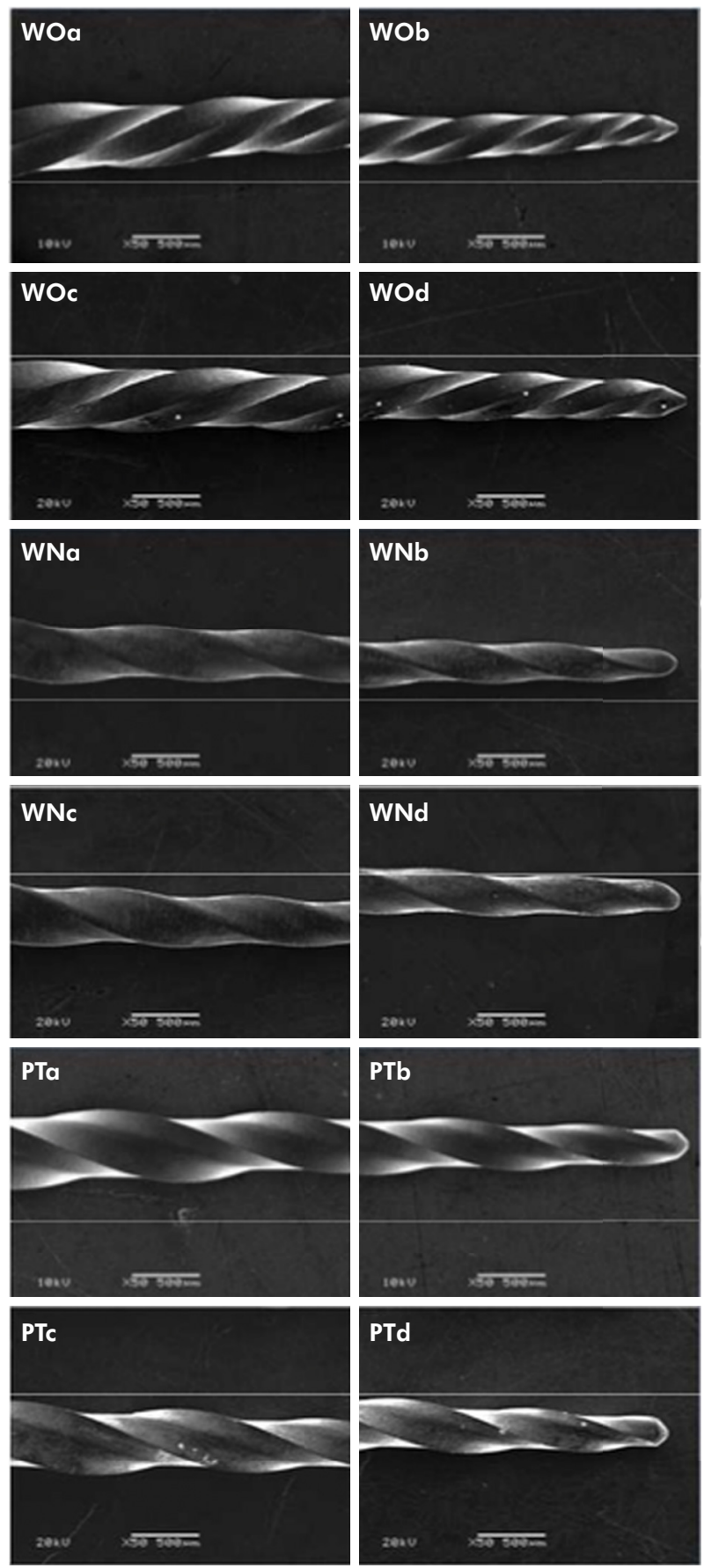

*indicates areas with defects along the examined shaft.

Figure 4. SEM images showing WaveOne (WO), Wizard Navigator (WN) and ProTaper (PT) instruments before $(a, b)$ and $\operatorname{after}(c, d)$ root canal instrumentation.

Consistent with our findings, Giannastasio et al. demonstrated similar transportation by $\mathrm{WN}$ and PT in simulated canals. ${ }^{23}$ Furthermore, as in the present study, previous studies did not find statistically significant
Table 2. Median and percentiles (25/75) of preparation time (minutes).

\begin{tabular}{lccc}
\hline Instruments & Median & Percentiles (25/75) & $p$ \\
\hline WaveOne & $1.31^{\mathrm{a}}$ & $1.02 / 1.43$ & - \\
Protaper & $2.18^{\mathrm{b}}$ & $2.05 / 2.31$ & - \\
Navigator & $2.18^{\mathrm{b}}$ & $2.07 / 2.39$ & 0.004 \\
\hline
\end{tabular}

*Different lowercase letters in the column indicate statistically significant difference $(p<.05)$.

difference between rotary and reciprocating systems in the apical third of root canals regarding canal transportation and centering ratio. $15,21,24,25$ The lack of difference between instruments at 1, 2,3 and $4 \mathrm{~mm}$ from the apical foramen, in the present investigation, may be attributed to the non-cutting tip and to the standardization of the apical diameter size of the tested instruments.

At $5 \mathrm{~mm}$ from the apical foramen, the WO group scored significantly higher for canal transportation than the WN and PT groups. This can be related to the different instrumentation kinematics and to the file design of WO, as well as to the root canal anatomy. The reciprocating motion, the modified convex triangular cross-section with radial lands at the tip and the convex triangular cross-section in the middle and coronal portion of the WO instrument could have contributed to this finding. ${ }^{26}$ Moreover, less tapered instruments, compared to larger ones, were better at maintaining the original canal curvature. ${ }^{15}$ This can be linked to the results of this study, considering that the WO primary instrument (25.08) has a larger taper than the finishing instruments used in the WN (W4 - 25.06) and PT groups (F2 - 25.08 at the tip, decreasing progressively to D16).

A previous investigation found radicular dentin wall thicknesses to be less than $1 \mathrm{~mm}$ toward the furcation at $5 \mathrm{~mm}$ from the apex of mesiobuccal roots from first maxillary molars. ${ }^{27}$ After root canal preparation, the absence of root canal transportation toward the so-called danger area results in more dentin remaining toward the furcation. The hypothesis that the amount of preserved structure will translate into enhanced clinical outcomes was not confirmed by clinical investigations. However, in the absence of a clinical study directly testing this hypothesis, it seems reasonable to consider that fracture is more frequent 
when dentin thickness is reduced. Based on the results of the present investigation, root canal preparation with WN and PT resulted in less dentin loss, thereby favoring tooth preservation.

The anticurvature method keeps the canal integrity in the thin portion (furcal region) and reduces the possibility of root perforation or stripping. ${ }^{28}$ However, the use of this method is limited when rotary and reciprocating systems are employed, due to the lower digital control over the file. Accordingly, the present investigation showed that WO may have weakened the furcal region at $5 \mathrm{~mm}$ from the apical foramen. In contrast, WN and PT presented lower canal transportation toward the furcation. Also, the different instrument kinematics may have contributed to these results.

SEM seems to be the most appropriate method to evaluate deformation of endodontic instruments; in addition, it has been used in other studies. ${ }^{18,29,30,31}$ No fracture occurred and only small defects were observed along the surface examined in the WO and PT groups, suggesting that all tested instruments are safe for the preparation of up to four root canals, which may represent a maxillary molar.

Instrumentation time depends on the operator's experience, on the used technique, and on the number of instruments employed. ${ }^{32}$ In line with our findings, some authors reported that instrumentation time, including irrigation procedures, is lower when WO instruments are used. ${ }^{15,22}$ This is expected as the WO system involves single-file instrumentation while WN and PT are multiple-file systems. The lower number of instrument changes and the shorter time required for

\section{References}

1. Pettiette MT, Delano EO, Trope M. Evaluation of success rate of endodontic treatment performed by students with stainless-steel K-files and nickel-titanium hand files. J Endod. 2001;27(2):124-7. doi:10.1097/00004770-200102000-00017

2. Kum KY, Spängberg L, Cha BY, Il-Young J, Seung-Jong L, Chan-Young L. Shaping ability of three ProFile rotary instrumentation techniques in simulated resin root canals. J Endod. 2000;26(12):719-23. doi:10.1097/00004770-200012000-00013

3. Schäfer E, Lohmann D. Efficiency of rotary nickel-titanium FlexMaster instruments compared with canal instrumentation makes the WO system clinically attractive. However, it is important to point out that the time difference between $\mathrm{WO}$ and the other tested systems represents a small difference in the whole time required for the treatment. Furthermore, especially in mesiobuccal roots, the anatomic aspect (mesiodistal flatness) contributes to the remaining untouched areas after instrumentation. Thus, short-time instrumentation may not permit enough contact time for irrigators to aid in the reduction of root canal infection. This emphasizes the importance of efficient root canal irrigation and mechanisms to improve the cleaning potential of irrigators, such as passive ultrasonic irrigation. ${ }^{33,34}$

\section{Conclusions}

Under the conditions of this ex vivo study, the $\mathrm{WN}$, $\mathrm{WO}$, and PT systems had a similar centering ratio in curved canals, with no significant procedural errors and structural changes on the file surface after root canal instrumentation. However, WO produced more canal transportation towards the furcation at the beginning of the apical third ( $5 \mathrm{~mm}$ from the apical foramen), but it completed root canal preparation faster than the WN and PT systems.

\section{Acknowledgments}

The authors would like to thank the Laboratório de Análise de Minerais e Rochas (LAMIR) of the Federal University of Paraná and the Centro de Microscopia e Microanálise (CMM) of the Federal University of Rio Grande do Sul for granting permission for micro-CT scanning and SEM, respectively. The authors deny any conflicts of interest.

stainless steel hand K-Flexofile - Part 1. Shaping ability in simulated curved canals. Int Endod J. 2002;35(6):505-13. doi:10.1046/j.1365-2591.2002.00513.x

4. Thompson SA, Dummer PM. Shaping ability of ProFile.04 Taper Series 29 rotary nickel-titanium instruments in simulated root canals. Part 1. Int Endod J. 1997;30(1):1-7. doi:10.1111/j.1365-2591.1997.tb01093.x

5. Thompson SA, Dummer PM. Shaping ability of ProFile.04 Taper Series 29 rotary nickel-titanium instruments in simulated root canals. Part 2. Int Endod J. 1997;30(1):8-15. doi:10.1111/j.1365-2591.1997.tb01092.x 
6. Ankrum MT, Hartwell GR, Truitt JE. K3 Endo, ProTaper, and ProFile systems: breakage and distortion in severely curved roots of molars. J Endod. 2004;30(4):234-7. doi:10.1097/00004770-200404000-00013

7. Pruett JP, Clement DJ, Carnes DL Jr. Cyclic fatigue testing of nickel-titanium endodontic instruments. J Endod. 1997;23(2):77-85. doi:10.1016/S0099-2399(97)80250-6

8. Bryant ST, Thompson SA, al-Omari MA, Dummer PM. Shaping ability of Profile rotary nickel-titanium instruments with ISO sized tips in simulated root canals: part 1. Int Endod J. 1998;31(4):275-81. doi:10.1046/j.1365-2591.1998.00153.x

9. Yared GM, Bou Dagher FE, Machtou P. Influence of rotational speed, torque and operator's proficiency on ProFile failures. Int Endod J. 2001;34(1):47-53. doi:10.1046/j.1365-2591.2001.00352.x

10. Li UM, Lee BS, Shih CT, Lan WH, Lin CP. Cyclic fatigue of endodontic nickel titanium rotary instruments: static and dynamic tests. J Endod. 2002;28(6):448-51. doi:10.1097/00004770-200206000-00007

11. Ounsi HF, Al-Shalan T, Salameh Z, Grandini S, Ferrari M. Quantitative and qualitative elemental analysis of different nickel-titanium rotary instruments by using scanning electron microscopy and energy dispersive spectroscopy. J Endod. 2008;34(1):53-5. doi:10.1016/j.joen.2007.09.009

12. Gavini G, Pessoa OF, Barletta FB, Vasconcellos MAZ, Caldeira CL. Cyclic fatigue resistance of rotary nickel-titanium instruments submitted to nitrogen ion implantation. J Endod. 2010;36(7):1183-6. doi:10.1016/j.joen.2010.03.032

13. Ye J, Gao Y. Metallurgical characterization of M-Wire nickel-titanium shape memory alloy used for endodontic rotary instruments during low-cycle fatigue. J Endod. 2012;38(1):105-7. doi: 10.1016/j.joen.2011.09.028

14. Gao Y, Gutmann JL, Wilkinson K, Maxwell R, Ammon D. Evaluation of the impact of raw materials on the fatigue and mechanical properties of ProFile Vortex rotary instruments. J Endod. 2012;38(3):398-401. doi:10.1016/j.joen.2011.11.004

15. Bürklein S, Poschmann T, Schäfer E. Shaping ability of different nickel-titanium systems in simulated S-shaped canals with and without glide path. J Endod. 2014;40(8):1231-4. doi:10.1016/j.joen.2014.01.043

16. Schneider SW. A comparison of canal preparations in straight and curved root canals. Oral Surg Oral Med Oral Pathol. 1971;32(2):271-5. doi:10.1016/0030-4220(71)90230-1

17. Gambill JM, Alder M, del Rio CE. Comparison of nickel-titanium and stainless steel hand-file instrumentation using computed tomography. J Endod. 1996;22(7):369-75. doi:10.1016/S0099-2399(96)80221-4

18. Troian CH, Só MVR, Figueiredo JAP, Oliveira EPM. Deformation and fracture of $\mathrm{RaCe}$ and $\mathrm{K} 3$ endodontic instruments according to the number of uses. Int Endod J. 2006;39(8):616-25. doi:10.1111/j.1365-2591.2006.01119.x

19. Fernandes LMPSR, Rice D, Ordinola-Zapata R, Capelozza ALA, Bramante CM, Jaramillo D et al. Detection of various anatomic patterns of root canals in mandibular incisors using digital periapical radiography, 3 cone-beam computed tomographic scanners, and micro-computed tomographic imaging. J Endod. 2014;40(1):42-5. doi:10.1016/j.joen.2013.09.039

20. Stern S, Patel S, Foschi F, Sherriff M, Mannocci F. Changes in centring and shaping ability using three nickel-titanium instrumentation techniques analysed by micro-computed tomography ( $\mu \mathrm{CT}$ ). Int Endod J. 2012;45(6):514-23. doi:10.1111/j.1365-2591.2011.02004.x

21. McRay B, Cox TC, Cohenca N, Johnson JD, Paranjpe A. A micro-computed tomography-based comparison of the canal transportation and centering ability of ProTaper Universal rotary and WaveOne reciprocating files. Quintessence Int. 2014;45(2):101-8. doi:10.3290/j.qi.a30998

22. Zhao D, Shen Y, Peng B, Haapasalo M. Root canal preparation of mandibular molars with 3 nickel-titanium rotary instruments: a micro-computed tomographic study. J Endod. 2014;40(11):1860-4. doi:10.1016/j.joen.2014.06.023

23. Giannastasio D, Rosa RA, Peres BU, Barreto MS, Dotto GN, Kuga MC et al. Wizard CD Plus and ProTaper Universal: analysis of apical transportation using new software. J Appl Oral Sci. 2013;21(5):468-74. doi:10.1590/1679-775720130229

24. Junaid A, Freire LG, Bueno CES, Mello I, Cunha RS. Influence of single-file endodontics on apical transportation in curved root canals: an ex vivo micro-computed tomographic study. J Endod. 2014;40(5):717-20. doi:10.1016/j.joen.2013.09.02

25. Capar ID, Ertas H, Ok E, Arslan H, Ertas ET. Comparative study of different novel nickel-titanium rotary systems for root canal preparation in severely curved root canals. J Endod. 2014;40(6):852-6. doi:10.1016/j.joen.2013.10.010

26. Berutti E, Chiandussi G, Paolino DS, et al. Effect of canal length and curvature on working length alteration with WaveOne reciprocating files. J Endod. 2011;37:1687-90. doi:10.1016/j.joen.2011.09.014

27. Degerness RA, Bowles WR. Dimension, anatomy and morphology of the mesiobuccal root canal system in maxillary molars. J Endod. 2010;36(6):985-9. doi:10.1016/j.joen.2010.02.017

28. Abou-Rass M, Frank AL, Glick DH. The anticurvature filing method to prepare the curved root canal. J Am Dent Assoc. 1980;101(5):792-4. doi:10.14219/jada.archive.1980.0427

29. Kottoor J, Velmurugan N, Gopikrishna V, Krithikadatta J. Effects of multiple root canal usage on the surface topography and fracture of two different $\mathrm{Ni}-\mathrm{Ti}$ rotary file systems. Indian J Dent Res. 2013;24(1):42-7. doi:10.4103/0970-9290.114942 
30. Rapisarda E, Bonaccorso A, Tripi TR, Condorelli GG, Torrisi L. Wear of nickel-titanium endodontic instruments evaluated by scanning electron microscopy: effect of ion implantation. J Endod. 2001;27(9):588-92. doi:10.1097/00004770-200109000-00009

31. Svec TA, Powers JM. The deterioration of rotary nickel-titanium files under controlled conditions. J Endod. 2002;28(2):105-7. doi:10.1097/00004770-200202000-00014

32. Paqué F, Musch U, Hülsmann M. Comparison of root canal preparation using RaCe and ProTaper rotary Ni-Ti instruments. Int Endod J. 2005;38(1):8-16. doi:10.1111/j.1365-2591.2004.00889.x
33. Almeida AP, Souza MA, Miyagaki DC, Dal Bello Y, Cecchin D, Farina AP. Comparative evaluation of calcium hypochlorite and sodium hypochlorite associated with passive ultrasonic irrigation on antimicrobial activity of a root canal system infected with Enterococcus faecalis: an in vitro study. J Endod. 2014;40(12):1953-7. doi:10.1016/j.joen.2014.08.025

34. Justo AM, Rosa RA, Santini MF, Ferreira MBC, Pereira JR, Duarte MAH et al. Effectiveness of final irrigant protocols for debris removal from simulated canal irregularities. J Endod. 2014;40(12):2009-14. doi:10.1016/j.joen.2014.08.006 